Article

\title{
Structural Characteristics of Multilayered Ni-Ti Nanocomposite Fabricated by High Speed High Pressure Torsion (HSHPT)
}

\author{
Gheorghe Gurau ${ }^{1}{ }^{(}$, Carmela Gurau ${ }^{1, *}$, Francisco Manuel Braz Fernandes ${ }^{2}$, Petrica Alexandru ${ }^{1}$, \\ Vedamanickam Sampath ${ }^{3}$, Mihaela Marin ${ }^{1}$ and Bogdan Mihai Galbinasu ${ }^{4}[$ \\ 1 Faculty of Engineering, “Dunărea de Jos” University of Galati, Domnească Street, 47, 800008 Galati, \\ Romania; gheorghe.gurau@ugal.ro (G.G.); Petrica.Alexandru@ugal.ro (P.A.); Mihaela.Marin@ugal.ro (M.M.) \\ 2 CENIMAT/I3N, Departamento de Ciências dos Materiais, Faculdade de Ciências e Tecnologia, \\ Universidade NOVA de Lisboa, 2829-516 Caparica, Portugal; fbf@fct.unl.pt \\ 3 Department of Metallurgical and Materials Engineering, Indian Institute of Technology Madras, \\ Chennai 600036, India; vsampath@iitm.ac.in \\ 4 Faculty of Dentistry, U.M.F. University of Medicine and Pharmacy "Carol Davila”, Bucharest, Dionisie Lupu, \\ Street, 37, 020021 Bucharest, Romania; bogdan.galbinasu@umfcd.ro \\ * Correspondence: carmela.gurau@ugal.ro; Tel.: +40-720-044084
}

Received: 30 October 2020; Accepted: 29 November 2020; Published: 4 December 2020

check for updates

\begin{abstract}
It is generally accepted that severe plastic deformation (SPD) has the ability to produce ultrafinegrained (UFG) and nanocrystalline materials in bulk. Recent developments in high pressure torsion (HPT) processes have led to the production of bimetallic composites using copper, aluminum or magnesium alloys. This article outlines a new approach to fabricate multilayered Ni-Ti nanocomposites by a patented SPD technique, namely, high speed high pressure torsion (HSHPT). The multilayered composite discs consist of Ni-Ti alloys of different composition: a shape memory alloy (SMA) Ti-rich, whose Mf $>$ RT, and an SMA Ni-rich, whose Af $<$ RT. The composites were designed to have 2 to 32 layers of both alloys. The layers were arranged in different sequences to improve the shape recovery on both heating and cooling of nickel-titanium alloys. The manufacturing process of $\mathrm{Ni}-\mathrm{Ti}$ multilayers is explained in this work. The evolution of the microstructure was traced using optical, scanning electron and transmission electron microscopes. The effectiveness of the bonding of the multilayered composites was investigated. The shape memory characteristics and the martensitic transition of the nickel-titanium nanocomposites were studied by differential scanning calorimetry (DSC). This method opens up new possibilities for designing various layered metal-matrix composites achieving the best combination of shape memory, deformability and tensile strength.
\end{abstract}

Keywords: composites; HSHPT; nano multilayers; Ni-Ti; SPD

\section{Introduction}

Multilayered composites have attracted much attention in engineering design as a promising technique to develop a novel combination of physical and mechanical properties acquired from the individual characteristics of the incorporated materials [1-5]. Bimetallic shape memory composites are among the most widely investigated class of composites, offering better shape memory properties for the design of new decomplex applications [6].

Shape memory alloys are stimulus-responsive materials with two universal properties: superelasticity and shape memory effect [7,8]. The occurrence of martensite-to-austenite and austenite-to-martensite transitions gives rise to shape memory and superelastic responses $[9,10]$. Among these alloys, Ni-Ti SMAs are among the most interesting thermo-responsive SMAs that are 
capable of exhibiting reliable shape memory characteristics, in addition to presenting high ductility and strength [11]. Research on Ni-Ti shape memory alloys has been revived by controlling the "size-effect". Grain size reduction to the nano range greatly increases recovery stress [12]. The nanocrystalline (NC) or ultrafinegrained (UFG) microstructure significantly enhances the mechanical and shape memory characteristics in comparison with the coarse grained alloy of the same composition [13]. One way to refine the microstructure of the fabricated bulk UFG and nanostructured SMAs is severe plastic deformation (SPD) processing [14]. Most metal-matrix composites are obtained by accumulative roll bonding, a variant of the SPD technique, which also makes it possible to obtain multiple layers [15]. In addition, bimetallic "Ni-Ti/Ni-Ti" shape memory composites obtained by welding present large recoverable strain on heating and cooling [16], and are potential candidates for use as thermomechanical actuators $[7,9,17]$. In earlier work, the major problem of the formation of a thick brittle intermetallic layer was encountered, in particular in high temperature bonding processes [18]. Recent developments have led to the use of high pressure torsion (HPT) as an appropriate severe plastic deformation technique in the manufacturing of bimetallic composites [18].

The aim of our research is to study the structure and phase transformations of smart Ni-Ti multilayered composites obtained using the HSHPT technique. This process combines HPT and friction stir processing, and is capable of fabricating UFG discs of about $40 \mathrm{~mm}$ in diameter from different types of alloys [19-21]. In addition, a more dependable method to fabricate bulk UFG metallic composites is HSHPT. We fabricated an "Ni-Ti/Ni-Ti" composite with 2 to 32 multilayered discs. The HSHPT process helps achieve very good bonding, high-quality interfaces with no intermetallic layers and ultrafine-grained microstructure from individual Ni-Ti layers.

\section{Experimental Procedure}

For this study, multilayered shape memory $\mathrm{Ni}_{50.3} \mathrm{Ti} / \mathrm{Ni}_{49.6} \mathrm{Ti}$ composites were produced using HSHPT severe deformation at ambient temperature. The materials used in this investigation were cut from commercial shape memory $\mathrm{Ni}_{49.6} \mathrm{Ti}_{50.4}$ (at.\%) sheets and superelastic $\mathrm{Ni}_{50.3} \mathrm{Ti}_{49.7}$ (at.\%) rods. The martensitic transformation temperature Ms for the SMA that is rich in titanium is $51^{\circ} \mathrm{C}$, while it is $-16.5^{\circ} \mathrm{C}$ for Ni-rich alloy.

The details of the HSHPT procedure and the ad hoc machine used in the present work are given in our earlier papers $[19,21]$. To enable microstructural refinement concurrent with bonding of layers, the SPD process variables were chosen utilizing an EATON SVX024A1-4A1B1 frequency converter via PLC XC 200. The speed of rotation of the upper punch was maintained at $900 \mathrm{rpm}$. Initially, a pressure of 20 bars was applied using the bottom punch. The pressure levels monitored making use of the Hottinger Spider 8 equipment were between $0.01 \mathrm{GPa}$ and $0.68 \mathrm{GPa}$, depending on the number of layers. The maximum torque reached was $42 \mathrm{Nm}$. The processing time lasted between 11 and $28 \mathrm{~s}$. The maximum pressure was applied for less than $5 \mathrm{~s}$.

HSHPT was first applied on each Ni-rich sample (about $9.5 \mathrm{~mm} \times 7.4 \mathrm{~mm}$ and $2.35 \mathrm{~mm}$ in thickness) and Ti-rich sample (9.5 $\mathrm{mm}$ in diameter and $\sim 2.35 \mathrm{~mm}$ in thickness) with austenitic and martensitic structures, respectively, at room temperature. The second step involved was fabricating the composites. To obtain two- and three-layer composites, discs with different chemical compositions were made to overlap alternatively in different successions. In the third step, these modules were cut in half and assembled as sandwich stacks. Four-layered composites were obtained by halving the two-layered composite and overlapping the parts in the HSHPT machine. The same procedure was used to obtain 8,16 and 32 layers. Three-layered composites were obtained by overlapping the obtained Ti-rich, Ni-rich and T-rich disks. Five-layered composites were obtained by overlapping half of the obtained three- and two-layered composites. Six-layered composites were obtained by overlapping the obtained three-layered composite (Ti-rich, Ni-rich and T-rich half disks) with another three-layered composite (Ni-rich, Ti-rich and Ni-rich half disks). Nine-layered composites were obtained by overlapping the half of obtained four- and five-layered composites. Twelve-layered composites were obtained by overlapping the obtained 6-layered composite, and 24-layered composites 
were obtained by overlapping the obtained 12-layered composite (Figure 1). The cumulative degrees of deformation of multilayered bimetallic composites, calculated using the formula $\varepsilon=\frac{h_{0}}{h_{1}}$, (where $\mathrm{h}_{0}$ is initial thickness of the sample and $h_{1}$ is the final thickness of the sample), ranged from 0.95 to 4.65 . The SPD discs produced were with $\mathrm{d} \leq 40 \mathrm{~mm}$ and $\mathrm{t}=1.5-0.15 \mathrm{~mm}$.

Microstructural examinations highlighted the ability to manufacture multilayered composites and revealed the reliable bond of layers, as well the reduction in grain diameter accomplished using the HSHPT technique. Investigation of the multilayered $\mathrm{Ni}_{50,3} \mathrm{Ti}_{1} \mathrm{Ni}_{49,6} \mathrm{Ti}$ microstructure was done using an OLYMPUS BX51 (manufactured by Olympus microscopes, Tokyo, Japan) optical microscope, with the QCapture (QuickPHOTO MICRO 2.3, Prague, Czech Republic) software package, under bright and dark field modes. The microstructure was studied using a Zeiss (ZEISS EVO MA15, manufactured by Carl Zeiss Microscopy GmbH, Jena, Germany SEM/EDX (Scanning Electron Microscope coupled with Energy Dispersive X-ray analyzer) to study the grain structure and the quality of the joints.

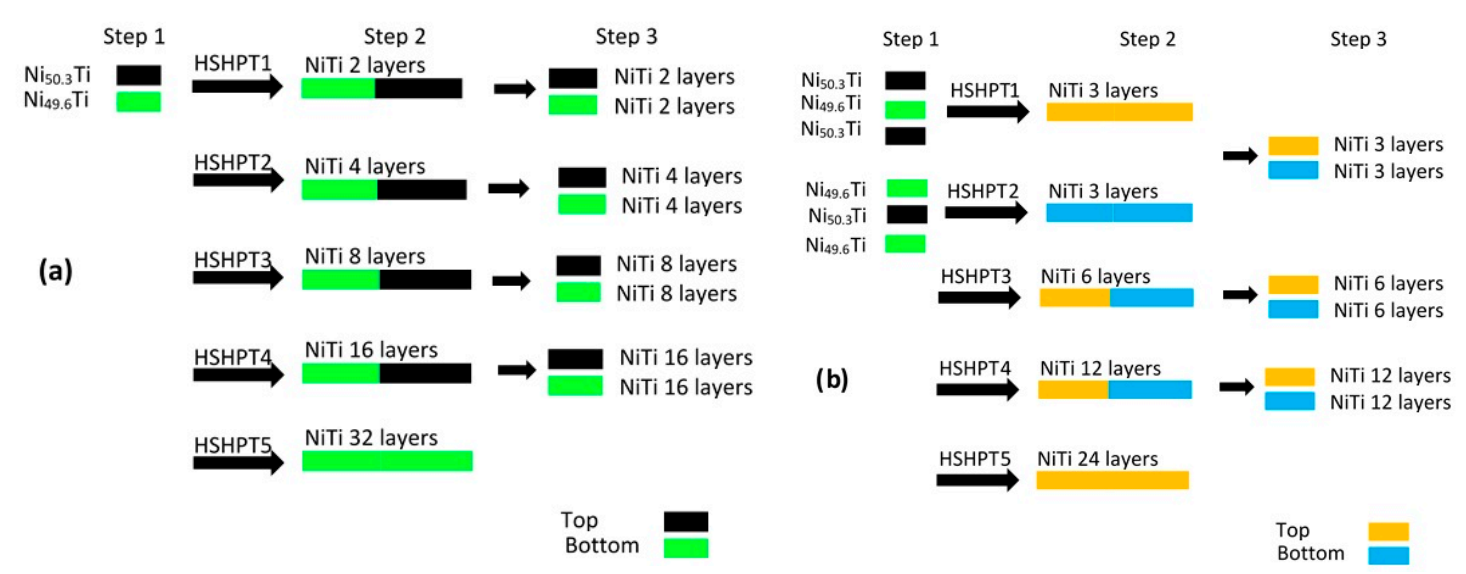

Figure 1. Processing route of $\mathrm{Ni}_{50.3} \mathrm{Ti} / \mathrm{Ni}_{49.6} \mathrm{Ti}$ composite discs cut in half and assembled as sandwich stacks with: (a) number of layers multiple of 2 and (b) number of layers multiple of 3.

An in-depth microstructural analysis was also carried out using a TEM (Transmission Electron Microscope, Model Tecnai 20G2, FEI, Hillsboro, OR, USA), operating at a voltage of $200 \mathrm{kV}$. The martensitic transformation temperatures were measured using a differential scanning calorimeter. The DSC tests were run using a DSC 204 F1 Phoenix model from Netzsch (Selb, Germany). The tests were performed between $-150{ }^{\circ} \mathrm{C}$ and $150{ }^{\circ} \mathrm{C}$ using a cooling and heating rate of $10^{\circ} \mathrm{C} / \mathrm{min}$, under a protective gaseous nitrogen atmosphere. Specimens $(15-20 \mathrm{mg})$ were obtained from the HSHPT discs for 4, 16, 32 layered composites:

- one set of samples from mid-radius of the discs,

- $\quad$ another set from the edge and the center of each disc.

Prior to DSC, an etching solution of HF:HNO3: H20 (1:5:10 in volume) was used to remove the oxidation of the surface layer and the regions affected by the cutting process.

\section{Results and Discussion}

\subsection{Optical Microscopy}

Figure 2 illustrates bright and dark field optical micrographs $(\mathrm{OM})$ of the multilayers observed in the $\mathrm{Ni}_{50.3} \mathrm{Ti} \mathrm{Ni}_{49.6} \mathrm{Ti}$ alloy composite, whose sample was cut as a cross-section around the middle of the discs. The bright field micrograph of the three-layered $\mathrm{Ni}_{50.3} \mathrm{Ti} / \mathrm{Ni}_{49.6} \mathrm{Ti} / \mathrm{Ni}_{50.3} \mathrm{Ti}$ alloy composite is shown in Figure 2a. 


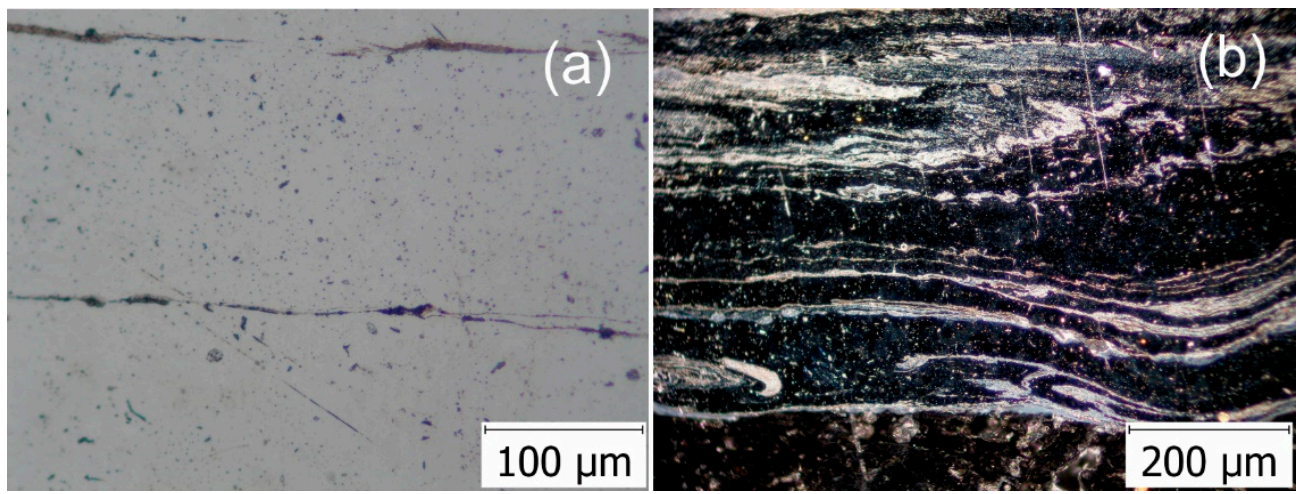

Figure 2. Optical micrograph of $\mathrm{Ni}_{50.3} \mathrm{Ti}_{/} \mathrm{Ni}_{49.6} \mathrm{Ti}$ composite discs: (a) bright field image of three layers and (b) dark field image of 24 layers.

This feature is consistent with the refined microstructure resulting from severe plastic deformation by HSHPT. While some precipitate particles could be observed, the grain boundaries were not resolved, as the size of the microstructural features was beyond the resolution range of the optical microscope. The bonding between the sheets was discontinuous, narrow and could hardly be detected, since the chemical compositions were almost the same. The dark field optical micrograph of the 24-layered composite (Figure 2b) showed flowlines and waviness, as highlighted by the color contrast. This is in good agreement with HPT findings for bi-layers in the $\mathrm{Al} / \mathrm{Mg}$ composite [18]. The thickness of the layers in this composite was about $22 \mu \mathrm{m}$. The interfacial layers were less obvious as the number of layers of the composite increased. The quality of the bonding was evident.

\subsection{SEM/EDX Analysis}

The SEM microstructure of the 12-layered specimen demonstrates a typical SPD structure (Figure 3a). The microstructural modification by HSHPT results from three opposing effects. In the first stage, low pressure and high speed of the punch act together, leading to an increase in temperature of the material to almost $800{ }^{\circ} \mathrm{C}$ (estimated using a temperature sensor-CT laser radiation pyrometer T2 MHCF OPTC).

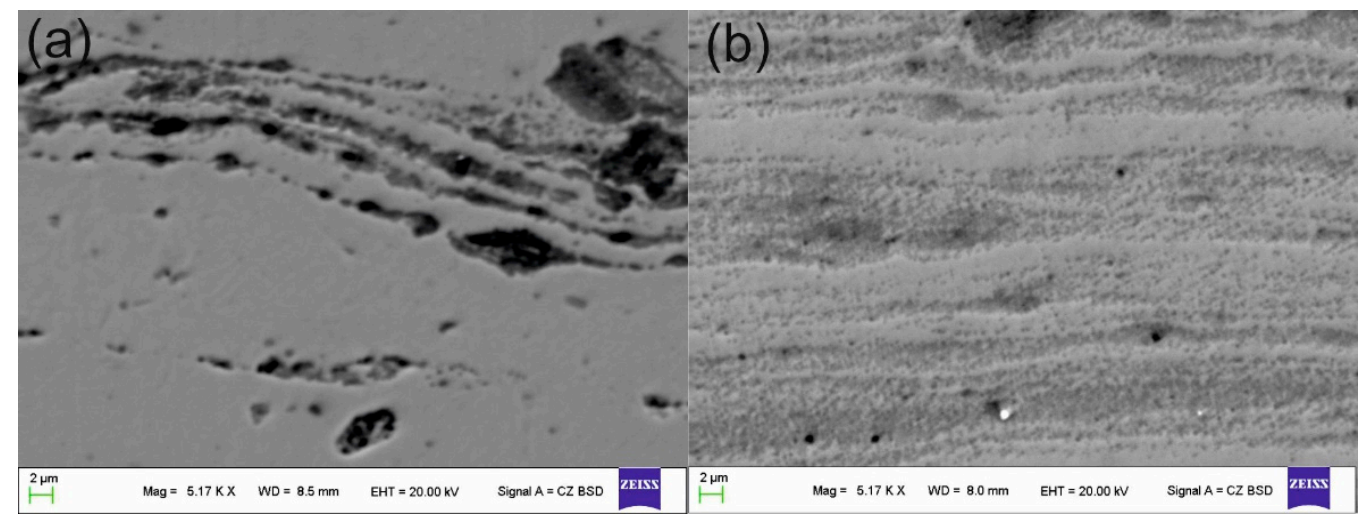

Figure 3. SEM image of HSHPT-processed metallic composite: (a) 12 layers, (b) 24 layers.

At this point, high pressure was exerted on the discs, leading to severe deformation. Besides shearing, recovery and recrystallization of grains took place due to the samples attaining high temperature. Grain refining during HSHPT should result from dynamic recrystallization that takes place at high temperature; it could be said that rapid cooling to room temperature "freezes" the UFG structure produced at high temperature. On the surface of the sample, only curved lines could be observed, and not grain boundaries. The materials were welded without a detectable intermediate 
area. The adhesion of layers was noticeable. The presence of smooth interfaces between layers was attributed to the specific condition created during HSHPT. Other methods of manufacturing the metallic composite led to the occurrence of an intermetallic layer at the interface.

To investigate the distribution of elements in the Ni rich/Ti-rich areas, a line scan by EDX was run on the nine layers of the disc (Supplementary material: Figure S1). The nine layers were emphasized by the variation of the $\mathrm{Ti}(\mathrm{a}$ ) and $\mathrm{Ni}(\mathrm{b})$ content, respectively. Across the layers (quasi $20 \mu \mathrm{m}$ ), alternating areas Ni-richer or Ti-richer could be identified. EDX characterization was performed in an area comprising the nine-layers of the composite. Figure S2 of the Supplementary Materials presents the opposing variations of $\mathrm{Ni}$ and $\mathrm{Ti}$ contents in the successive nine layers of the composite. The severity of plastic deformation introduced by HSHPT produced rotation and plastic flow of large volumes of material caused by upper punch rotation at high speeds [19]. The 3-D images of the surfaces (seen in Figure S2 of Supplementary Material) suggest the arrangement of the distinct layers.

\subsection{Transmission Electron Microscopy}

Figure 4 illustrates a TEM micrograph (bright field) of the four-layered $\mathrm{Ni}_{50.3} \mathrm{Ti} / \mathrm{Ni}_{49.6} \mathrm{Ti}$ composite. The UFG structure with an equiaxed morphology prevailed after HSHPT. The average size of the grains was about $200-300 \mathrm{~nm}$.

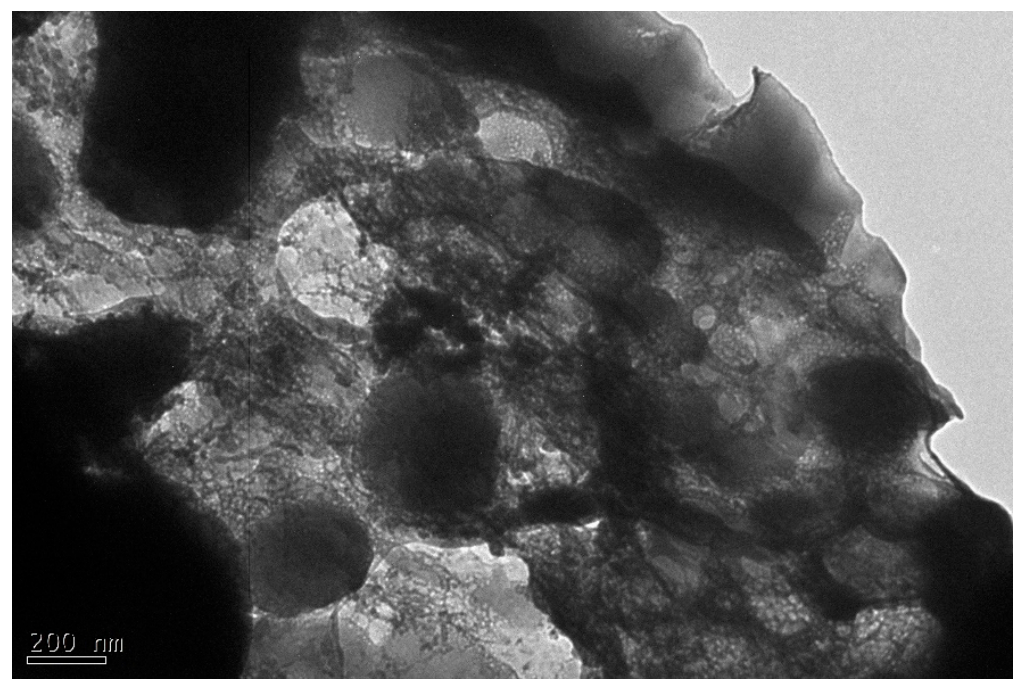

Figure 4. TEM image of the 4 layered $\mathrm{Ni}_{50.3} \mathrm{Ti} / \mathrm{Ni}_{49.6} \mathrm{Ti}$ composite.

The image highlights equiaxed subgrains isolated by dislocation cells. Between them, several nanograins were also interspersed. These grains, with a size of under $50 \mathrm{~nm}$, formed clear boundaries. Various dislocation cell configurations, including high-density dislocations, zones of dislocation tangles or condensed dislocation boundaries, were characteristic of the rather inhomogeneous microstructures of the sample.

\subsection{DSC}

The DSC curves for samples extracted from the midradius of the discs of the $\mathrm{Ni}_{50.3} \mathrm{Ti}_{1} \mathrm{Ni}_{49.6} \mathrm{Ti}$ composite with 4, 16 and 32 layers after HSHPT are shown in Figure 5. The equipment is capable of measuring temperatures in the range of $-150{ }^{\circ} \mathrm{C}$ to $150{ }^{\circ} \mathrm{C}$, covering the martensite transformation temperature range for both alloys. The thermograms of severe plastic-deformed composites revealed two peaks upon heating and two peaks after cooling. It was possible to identify the transformation temperatures corresponding to the Ni-rich (lower temperatures) and Ti-rich (higher temperatures) SMAs. The peaks between $80{ }^{\circ} \mathrm{C}$ and $120{ }^{\circ} \mathrm{C}$ represented the martensite (B19')-to-austenite (B2) reversible transformation for the shape memory $\mathrm{Ni}_{49.6} \mathrm{Ti}_{50.4}$ (Ti-rich) alloy. 


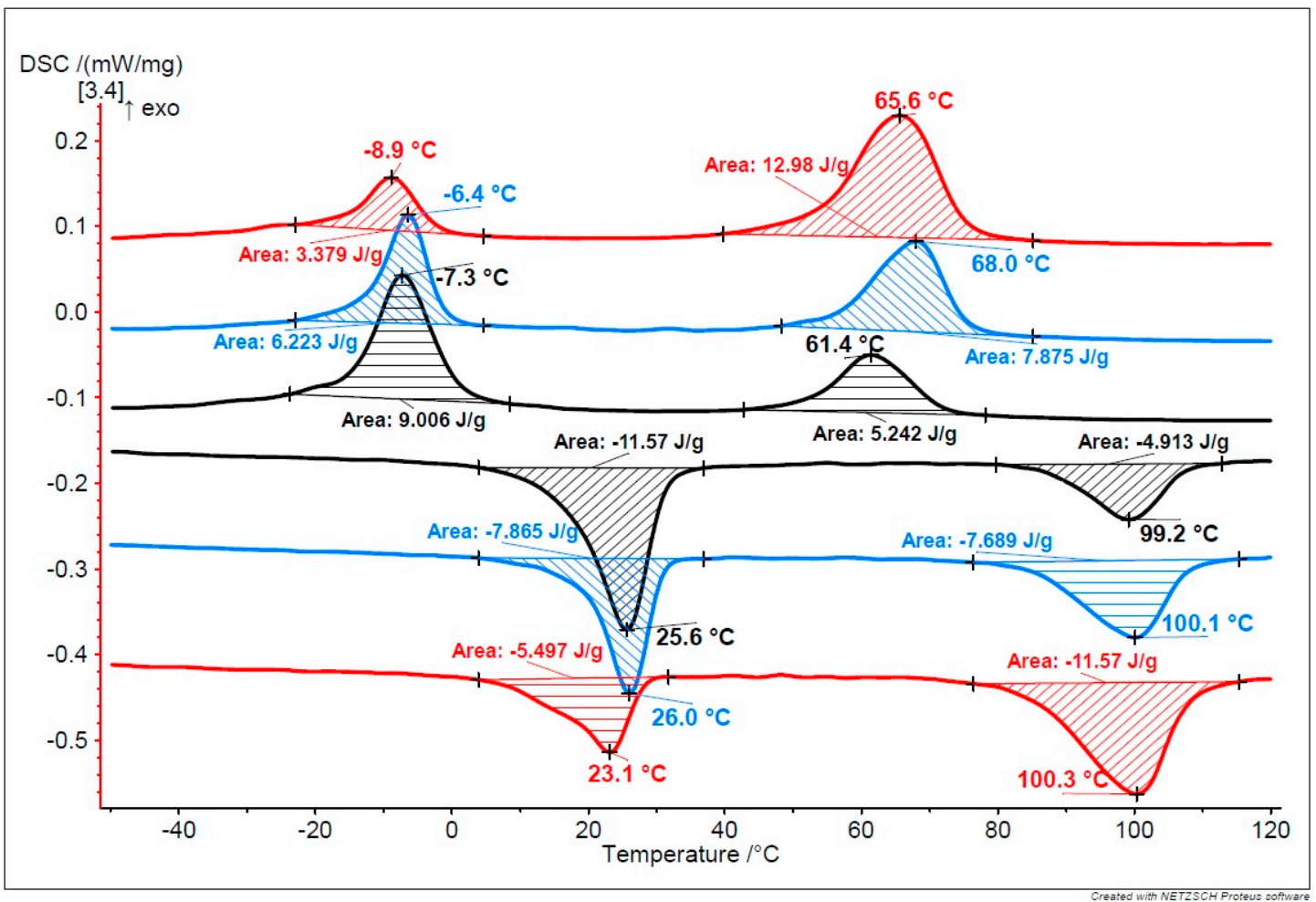

Figure 5. DSC curves of the 4 (black), 16 (blue) and 32 (red) layered $\mathrm{Ni}_{50.3} \mathrm{Ti} / \mathrm{Ni}_{49.6} \mathrm{Ti}$ composites after HSHPT.

The peaks between $10{ }^{\circ} \mathrm{C}$ and $-30^{\circ} \mathrm{C}$ represented the austenite (B2)-to-martensite (B19') reversible transformation for Ni-rich $\mathrm{Ni}_{50.3} \mathrm{Ti}_{49.7}$ alloy. Making successive deformation to produce 4, 16, 32 layers of composite did not significantly change the transformation temperatures. This result was obtained despite the fact that the degrees of deformation of the multilayered bimetallic composites with 4,16 and 32 layers ranged from 1.17, 2.41 to 4.65 . Likewise, the grain size was significantly reduced, while the cumulative degree of deformation increased. The reasonably stable transformation temperatures may be explained by the fact that the HSHPT process imposed a complex strain due to the high pressure concomitant with high rotational speed of the upper punch. The friction between punches and sample heated the severely plastic-deformed disc, thereby contributing to the rearrangement and decrement of the lattice defects. However, the intensity of the peaks was seen to decrease slightly with the increasing number of layers.

On the other hand, the Ms temperature slightly increased in the initial state in both alloys, as compared to the Ni-Ti SMAs that were rich in titanium and nickel. These results can be attributed to the grain refinement brought about by severe plastic deformation.

The $\mathrm{Ni}_{50.3} \mathrm{Ti}_{1} / \mathrm{Ni}_{49.6} \mathrm{Ti}$ composite showed reversible martensitic transformation subsequent to SPD. Postdeformation annealing was not required in contrast to deformation using other severe plastic deformation methods. The HSHPT technique combines SPD imposed on the sample at RT by HPT with PDA caused due to the heat generated because of friction occurring between the anvils and the sample.

Another important element that could be observed was the absence of the second step of the martensitic transformation, even in the Ni-Ti SMA that was rich in nickel. In the initial state, this alloy showed a two-stage phase transition of B19' $\leftrightarrow$ R-phase $\leftrightarrow$ B2 (Figure S3 of Supplementary Materials). But the DSC curves corresponding to severely plastic-deformed discs exhibited just one strong transformation stage, namely B19' $\leftrightarrow$ B2. After HSHPT, the intermediate R-phase transition was suppressed, as observed in our earlier results from research on a Ni-rich Ni-Ti alloy [22].

The DSC curves at the center and edge of the disc, which had 32 layers after processing, are illustrated in Figure 6. 


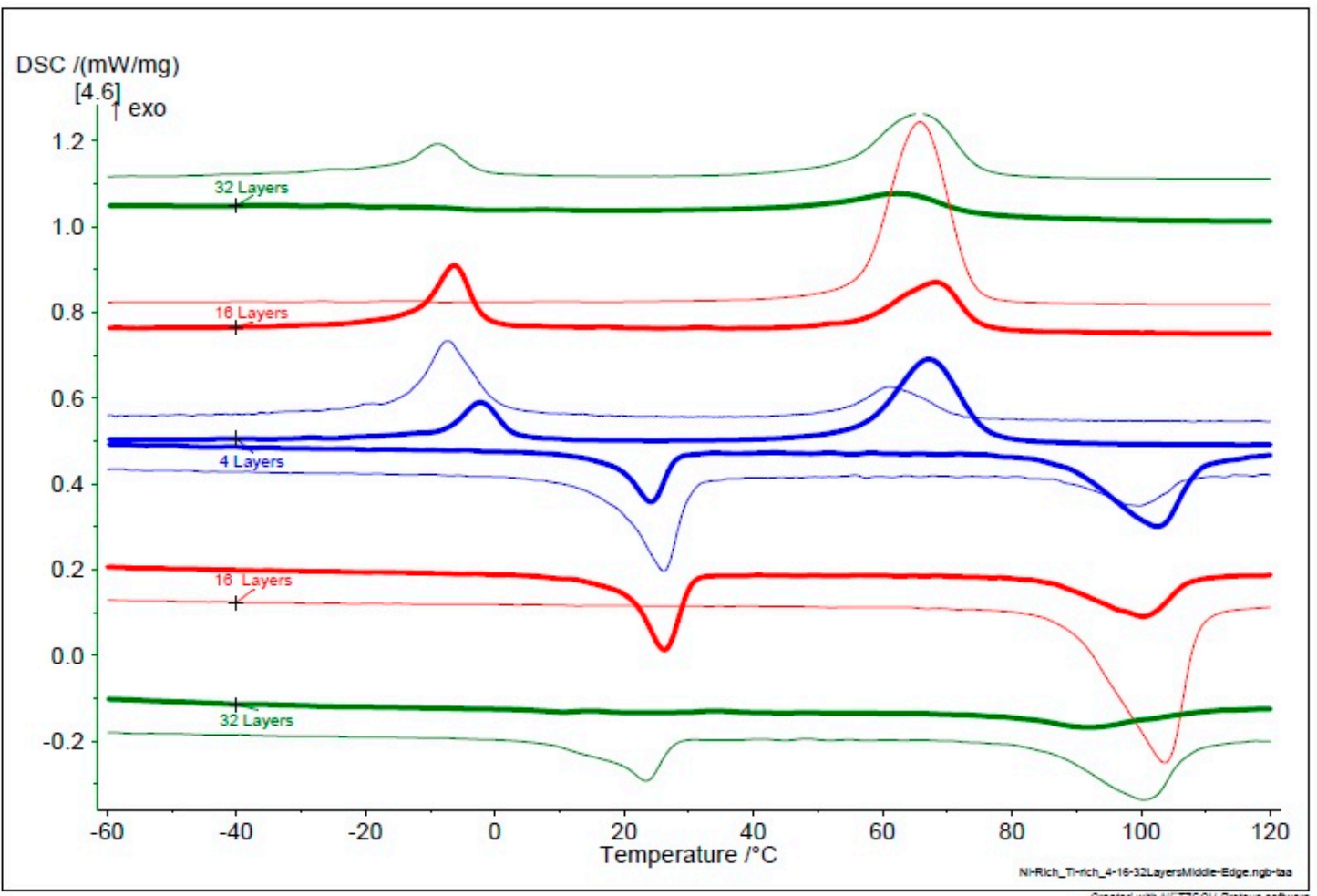

Figure 6. DSC curves for the 32 layers of $\mathrm{Ni}_{50.3} \mathrm{Ti}_{1} / \mathrm{Ni}_{49.6}$ Ti composite after HSHPT. Thicker lines: center sample; thinner lines: edge sample.

In the HSHPT condition, the DSC curves revealed two peaks upon cooling and two upon heating, both for the edge sample and the middle sample only in the four-layered composite; for the 16and 32-layered samples, the DSC peaks associated with the Ni-rich layers were observed only for the center and edge samples, respectively. The exothermic and endothermic peaks of the Ti-rich alloy broadened, perhaps because of the increased density of the dislocations. The severe plastic deformation of Ni-rich alloy led to a considerable broadening of the exothermic peaks which were, however, still visible. Processing by HSHPT is complex because the imposed strain varies, both with the rotational speed of superior punch applied to the composite and with the position within the disc. Consequently, the thickness of the discs was slightly higher at the center where the cooling speed would be expected to decrease. The microstructure developed more rapidly at the edge than at the center of the disc in all plastic deformation processes by torsion at high pressure. The absence of transformation peaks associated with the Ni-rich alloy could be related to heterogeneous deformation of the HSHPT material [23].

\section{Conclusions}

In summary, a new SPD method, HSHPT, can successfully be used to manufacture bimetallic composites with an ultrafine grained structures. The achieved shape memory multilayer composites were composed of 2 to 32 layers of $\mathrm{Ni}_{50.3} \mathrm{Ti}$ and $\mathrm{Ni}_{49.6} \mathrm{Ti}$ alloys. The bonding of layers was achieved mainly by the high pressure imposed and short time high temperature reached during the high speed rotation of upper anvil. A very good joint was obtained, regardless of the number of layers or alternating them. The microstructure of composites was uniform where the bonding of adjacent layers could not be detected by optical microscopy and SEM. The SPD process was effective at refining both the alloys that made up the composite. As-HSHPT processed composite discs revealed martensitic transformation after deformation. The module diameter varied between 20 and $40 \mathrm{~mm}$, and was dependent on the number of layers and the degree of deformation applied. The thickness of the layers varied from $300 \mu \mathrm{m}$ to $20 \mu \mathrm{m}$. HSHPT yields multilayered, fine structures and may, in future study, be adapted 
for use for two-way SME. Future work will be also focus on the fabrication the new metallic UFG composites by HSHPT. This technology is capable of inducing thermocompression bonding starting from dissimilar materials. Multilayer composites with desirable mechanical, electrical, magnetic and biocompatibility properties provide the opportunity to create effective functional applications.

Supplementary Materials: The following are available online at http://www.mdpi.com/2075-4701/10/12/1629/s1.

Author Contributions: Conceptualization, C.G. and G.G.; methodology, C.G., G.G., F.M.B.F., P.A., V.S., M.M. and. B.M.G. investigation, C.G., P.A., M.M. and B.M.G. (OM, SEM), F.M.B.F. (DSC) and V.S. (TEM); writing-original draft preparation, C.G. and G.G.; writing-review and editing, V.S., G.G., C.G. and P.A. supervision, F.M.B.F. and V.S.; project administration, C.G. and G.G.; All authors have read and agreed to the published version of the manuscript.

Funding: This research was funded by 47PCCDI/2018 project and MANUNET 3 PN3-P3-302, grant number 99-2019. F.M. Braz Fernandes acknowledges the funding of CENIMAT/I3N by National Funds through the FCT Fundação para a Ciência e a Tecnologia, I.P., within the scope of the project ref ${ }^{a}$ UIDB/50025/2020-2023. Edgar Camacho (CENIMAT, FCT/UNL) is acknowledged for running the DSC tests.

Conflicts of Interest: The authors declare no conflict of interest. The funders had no role in the design of the study; in the collection, analyses, or interpretation of data; in the writing of the manuscript, or in the decision to publish the results.

\section{References}

1. Ji, X.; Wang, Q.; Yin, F.; Cui, C.; Ji, P.; Hao, G. Fabrication and properties of novel porous CuAlMn shape memory alloys and polymer/CuAlMn composites. Compos. Part A Appl. Sci. Manuf. 2018, 107, 21-30. [CrossRef]

2. Yi, X.; Sun, K.; Gao, W.; Meng, X.; Cai, W.; Zhao, L. Microstructure design of the excellent shape recovery properties in (Ti,Hf) 2Ni/Ti-Ni-Hf high temperature shape memory alloy composite. J. Alloys Compd. 2017, 729, 758-763. [CrossRef]

3. Huang, G.Q.; Yan, Y.F.; Wu, J.; Shen, Y.F.; Gerlich, A.P. Microstructure and mechanical properties of fine-grained aluminum matrix composite reinforced with nitinol shape memory alloy particulates produced by underwater friction stir processing. J. Alloys Compd. 2019, 786, 257-271. [CrossRef]

4. Oliveira, J.P.; Duarte, J.F.; Inácio, P.; Schell, N.; Miranda, R.M.; Santos, T.G. Production of Al/NiTi composites by friction stir welding assisted by electrical current. Mater. Des. 2017, 113, 311-318. [CrossRef]

5. Wang, E.; Tian, Y.; Wang, Z.; Jiao, F.; Guo, C.; Jiang, F. A study of shape memory alloy NiTi fiber/plate reinforced (SMAFR/SMAPR) Ti-Al laminated composites. J. Alloys Compd. 2017, 696, 1059-1066. [CrossRef]

6. Belyaev, S.; Rubanik, V.; Resnina, N.; Rubanik, V.; Demidova, E.; Lomakin, I. Bimetallic shape memory alloy composites produced by explosion welding: Structure and martensitic transformation. J. Mater. Process. Technol. 2016, 234, 323-331. [CrossRef]

7. Lohan, N.M.; Pricop, B.; Popa, M.; Matcovschi, E.; Cimpoeşu, N.; Cimpoeşu, R.; Istrate, B.; Bujoreanu, L.G. Hot Rolling Effects on the Microstructure and Chemical Properties of NiTiTa Alloys. J. Mater. Eng. Perform. 2019, 28, 7273-7280. [CrossRef]

8. Cimpoesu, N.; Mihalache, E.; Lohan, N.M.; Suru, M.G.; Comãneci, R.I.; Özkal, B.; Bujoreanu, L.G.; Pricop, B. Structural-Morphological Fluctuations Induced by Thermomechanical Treatment in a Fe-Mn-Si Shape Memory Alloy. Met. Sci. Heat Treat. 2018, 60, 471-477. [CrossRef]

9. Oliveira, J.P.; Miranda, R.M.; Fernandes, F.M.B. Welding and Joining of NiTi Shape Memory Alloys: A Review. Prog. Mater. Sci. 2017, 88, 412-466. [CrossRef]

10. Sun, L.; Huang, W.M.; Ding, Z.; Zhao, Y.; Wang, C.C.; Purnawali, H.; Tang, C. Stimulus-responsive shape memory materials: A review. Mater. Des. 2012, 33, 577-640. [CrossRef]

11. Soejima, Y.; Motomura, S.; Mitsuhara, M.; Inamura, T.; Nishida, M. In situ scanning electron microscopy study of the thermoelastic martensitic transformation in Ti-Ni shape memory alloy. Acta Mater. 2016, 103, 352-360. [CrossRef]

12. Tsuchiya, K.; Hada, Y.; Koyano, T.; Nakajima, K.; Ohnuma, M.; Koike, T.; Todaka, Y.; Umemoto, M. Production of TiNi amorphous/nanocrystalline wires with high strength and elastic modulus by severe cold drawing. Scr. Mater. 2009, 60, 749-752. [CrossRef] 
13. Jiang, D.; Jiang, J.; Shi, X.; Jiang, X.; Jiao, S.; Cui, L. Constrained martensitic transformation in nanocrystalline TiNi/NbTi shape memory composites. J. Alloys Compd. 2013, 577, S749-S751. [CrossRef]

14. Tohidi, A.A.; Ketabchi, M.; Hasannia, A. Nanograined Ti-Nb microalloy steel achieved by Accumulative Roll Bonding (ARB) process. Mater. Sci. Eng. A 2013, 577, 43-47. [CrossRef]

15. Ana, S.V.A.; Reihanian, M.; Lotfi, B. Accumulative roll bonding (ARB) of the composite coated strips to fabricate multi-component Al-based metal matrix composites. Mater. Sci. Eng. A 2015, 647, 303-312. [CrossRef]

16. Belyaev, S.; Rubanik, V.; Resnina, N.; Lomakin, I.; Demidova, E. Reversible strain in bimetallic TiNi-based shape memory composites produced by explosion welding. Mater. Today Proc. 2017, 4, 4696-4701. [CrossRef]

17. Oliveira, J.P.; Zeng, Z.; Andrei, C.; Braz Fernandes, F.M.; Miranda, R.M.; Ramirez, A.J.; Omori, T.; Zhou, N. Dissimilar laser welding of superelastic NiTi and CuAlMn shape memory alloys. Mater. Des. 2017, 128, 166-175. [CrossRef]

18. Qiao, X.; Li, X.; Zhang, X.; Chen, Y.; Zheng, M.; Golovin, I.S.; Gao, N.; Starink, M.J. Intermetallics formed at interface of ultrafine grained $\mathrm{Al} / \mathrm{Mg}$ bi-layered disks processed by high pressure torsion at room temperature. Mater. Lett. 2016, 181, 187-190. [CrossRef]

19. Gurau, G.; Gurau, C.; Bujoreanu, L.G.; Sampath, V. A Versatile Method for Nanostructuring Metals, Alloys and Metal Based Composites. In Proceedings of the IOP Conference Series: Materials Science and Engineering, Iasi, Romania, 25-26 May 2017; pp. 24-27.

20. Gurau, G.; Gurau, C.; Sampath, V.; Bujoreanu, L.G. Investigations of a nanostructured FeMnSi shape memory alloy produced via severe plastic deformation. Int. J. Miner. Metall. Mater. 2016, 23, 1315-1322. [CrossRef]

21. Gurău, G.; Gurău, C.; Potecaşu, O.; Alexandru, P.; Bujoreanu, L.-G. Novel high-speed high pressure torsion technology for obtaining Fe-Mn-Si-Cr shape memory alloy active elements. J. Mater. Eng. Perform. 2014, 23, 2396-2402. [CrossRef]

22. Fernandes, F.M.B.; Mahesh, K.K.; Silva, R.J.C.; Gurau, C.; Gurau, G. XRD study of the transformation characteristics of severely plastic deformed Ni-Ti SMAs. Phys. Status Solidi C 2010, 7, 1348-1350. [CrossRef]

23. Ghat, M.; Mehtedi, M.E.; Ciccarelli, D.; Paoletti, C.; Spigarelli, S.; Mehtedi, M.E.; Ciccarelli, D.; Paoletti, C.; High, S.S. Materials at High Temperatures High temperature deformation of IN718 superalloy: Use of basic creep modelling in the study of Nickel and single-phase Ni-based superalloys. Mater. High Temp. 2019, 3409, $1-10$.

Publisher's Note: MDPI stays neutral with regard to jurisdictional claims in published maps and institutional affiliations.

(C) 2020 by the authors. Licensee MDPI, Basel, Switzerland. This article is an open access article distributed under the terms and conditions of the Creative Commons Attribution (CC BY) license (http://creativecommons.org/licenses/by/4.0/). 